\title{
A PRODUÇÃO DE LUGARES NA FORMAÇÃO DOCENTE: EXPERIÊNCIAS NO LABORATÓRIO DE ENSINO DE HISTÓRIA DA UFGD
}

\author{
THE SEATS PRODUCTION IN TEACHER TRAINING: \\ EXPERIENCES IN HISTORY TEACHING LABORATORY OF UFGD
}

\author{
Nauk Maria de Jesus ${ }^{1}$ \\ Fernando Perli
}

\begin{abstract}
RESUMO: Este artigo tem como objetivo demonstrar como o curso de História da Universidade Federal da Grande Dourados (UFGD), uma universidade nova, localizada num espaço fronteiriço marcado pela diversidade cultural, por desigualdades e conflitos sociais, tem atuado na formação de professores de História, tendo como foco de análise o Laboratório de Ensino de História (LABhis). Ao mesmo tempo, objetivamos socializar experiências que construíram um lugar requerido nos últimos anos pelo curso num período compreendido entre 2006 e 2015.
\end{abstract}

PALAVRAS-ChAVE: Dourados-MS. Laboratório de Ensino de História. Ensino Pesquisa

\footnotetext{
ABSTRACT: This article aims to demonstrate how the course of history of Universidade Federal da Grande Dourados (UFGD), a new university, located in a border area marked by cultural diversity, by inequalities and social conflicts, has acted in the formation of teachers of history, focusing on the analysis of History Teaching Laboratory (LABhis). At the same time, we aim socialize experiences that built a place defendant in recent years by the course in a period between 2006 and 2015.
}

KEYWORDS: Dourados-MS. History Teaching Lab. Education - Research

1 Professora do Curso de Graduação e Pós-Graduação em História (Doutorado e Mestrado) da Universidade Federal da Grande Dourados (UFGD). Doutora em História pela Universidade Federal Fluminense (UFF).

2 Professor do Curso de Graduação e Pós-Graduação em História (Doutorado e Mestrado) da Universidade Federal da Grande Dourados (UFGD). Doutor em História pela Universidade Estadual Paulista Júlio de Mesquita Filho (UNESP/Assis). 


\section{Introdução}

[...] Que seja dito e repetido à exaustão: uma aula pode ser extremamente conservadora e ultrapassada contando com todos os mais modernos meios audiovisuais. Uma aula pode ser muito dinâmica e inovadora utilizando giz, professor e aluno. Em outras palavras, podemos utilizar meios novos, mas é a própria concepção de História que deve ser repensada. O recorte que o professor faz é uma opção política. Por mais antiga que pareça essa afirmação, ela se tornou muito importante num país como o nosso, redemocratizado nos aspetos formais, mas com padrões de desigualdades de fazer inveja aos genocídios clássicos do passado... (KARNAL, 2008, p. 9).

O fragmento acima nos sugere duas questões que permeiam o presente artigo. Uma, trata da condição que diferentes lugares e suportes técnicos ocupam na formação de professores de História. Outra, diz respeito ao contato do futuro profissional de História com realidades sociais marcadas por desigualdades e pela diversidade cultural.

O conceito "lugar" nos diz muito, pois ele permeia discussões daquilo que consideramos "fazer história" (CERTEAU, 2000, p. 66-77). Num jogo de escalas, para ilustrar onde estamos e o que pretendemos, podemos usá-lo para definir as tensões sociais que se fazem na fronteira entre Brasil e Paraguai, onde está situada a cidade de Dourados e a Universidade Federal Grande Dourados (UFGD). ${ }^{3}$

A UFGD, criada em 2005, possui entre os seus cursos, o de História (Licenciatura e Bacharelado), Mestrado e Doutorado, e nela antes de sua criação, quando ainda pertencia a Universidade Federal de Mato Grosso do Sul (UFMS), foi discutido pelo corpo docente o fortalecimento da área de ensino e Estágio, bem como a criação do Laboratório de Ensino de História (LABhis). Na transição de uma universidade para outra, surgiu o laboratório (2006) que no decorrer dos

\footnotetext{
3 O município de Dourados está localizado na porção meridional do Estado de Mato Grosso do Sul, a $220 \mathrm{~km}$ da capital Campo Grande, na denominada Região da Grande Dourados, composta pelos municípios de Maracaju, Rio Brilhante, Itaporã, Douradina, Deodápolis, Fátima do Sul, Vicentina, Glória de Dourados, Jateí e Caarapó. Apesar desta delimitação geográfica, Dourados polariza municípios que integram outras regiões do Estado, como a Sul-Fronteira, a Cone-Sul, a Leste, a de Campo Grande e a Sudoeste, englobando 37 municípios que, segundo a população estimada em 2013 pelo Instituto Brasileiro de Geografia e Estatística (IBGE), aproximam-se de 850.000 habitantes (PPC História, 2015, p. 10).
} 
anos, tornou-se um espaço de reflexão dos problemas e das perspectivas do curso de História, carregando marcas políticas em sua configuração física, discursiva e simbólica. Assim, em escala menor, neste artigo, tratamos das experiências e do lugar ocupado pelo Laboratório de Ensino de História no curso de História da UFGD, num período compreendido entre 2006 e $2015 .^{4}$

Para tratar da institucionalização e das experiências desenvolvidas no LABhis/UFGD utilizamos, além da documentação administrativa, entrevistas com professores do curso, que em diferentes momentos vivenciaram a construção do espaço. Ao propor este artigo pretendemos mostrar como uma universidade nova, localizada num espaço fronteiriço marcado pela diversidade cultural, por desigualdades e conflitos sociais, tem atuado na formação de professores de História. Ao mesmo tempo, objetivamos socializar experiências que construíram um lugar requerido nos últimos anos pelo curso, o que se aproxima de posturas de outras graduações em História e permite problematizar os avanços e os desafios do ensino de História no Brasil.

\section{As (in) definições do conceito e do lugar}

Embora a terminologia "laboratório de ensino" tenha encontrado resistências advindas daqueles que a entendem como espaço aplicado as áreas com suportes de pesquisas experimentais, a aplicação do conceito no campo da História configurou-se de outro modo. Nele, a prática reflexiva, a organização de grupos de pesquisa e materiais didáticos para serem aplicados na educação básica e subsidiarem a formação docente em cursos de licenciatura em História ganham relevância.

Projetos para formar, organizar, manter e revitalizar laboratórios de ensino em instituições de ensino superior no Brasil, apesar de serem práticas pontuais no cenário das licenciaturas de ciências humanas, nas últimas décadas, tornaram-se estratégias para a formação docente, para a articulação de grupos

\footnotetext{
4 A partir de 2002 foram intensificadas as discussões sobre as práticas de ensino no curso de História.
} 
de pesquisa em ensino e para a promoção de debates sobre as condições e perspectivas das licenciaturas em História.

Nos anos 1980, alguns espaços foram organizados para promover reflexões teóricas, pesquisas e metodologias no ensino de História. Das experiências iniciais podemos mencionar o Laboratório de Ensino e Aprendizagem em História (1982) da Universidade Federal de Uberlândia (UFU), o Laboratório de História Oral e Imagem (1982) da Universidade Federal Fluminense (UFF) e o Laboratório de Pesquisa e Ensino de História e Geografia (1986) da Universidade Federal de Santa Maria (UFSM).

Nessa época, as projeções desses lugares apontavam a pesquisa e a sistematização de materiais como prática que daria suporte para o ensino de História. De maneira mais visível, o ensino foi apresentado como questão central a partir da proposta e criação do Laboratório de Ensino de História (1994) da Universidade Estadual de Londrina (UEL), tendo como objetivo o diálogo entre a educação básica, o ensino superior e a pós-graduação.

A conquista de um laboratório pelo curso de História da UEL foi marcada por impasses e tensões. Conforme apontamentos de professores, a universidade não queria registrar o projeto devido a forte relação do conceito com as denominadas "ciências duras", que entendiam o espaço como de experimentação. A defesa dos docentes foi no sentido de que o laboratório era um lugar de "reflexão do passado" com epistemologia e regras metodológicas da História. Para Marin (2013), ao estudar experiências de laboratórios de ensino de História no Brasil e em Portugal, as articulações e demandas de docentes reforçaram:

[...] a ideia de laboratórios como espaços de debates sobre experiências, incertezas, partilha de dificuldades, erros e acertos que acadêmicos e professores têm a partir de suas vivências, seja no processo de formação inicial ou continuada da docência (MARIN, 2013, p. 126-127).

Neste sentido, a partir de apontamentos de professores envolvidos com a produção destes lugares, foi possível perceber que o surgimento de laboratórios, além de lançar perspectivas de instrumentalização, agregou em cursos de graduação e pós-graduação professores-pesquisadores dispostos a discutir 
temáticas de ensino sem possuírem relações específicas com o ensino de História.

A partir destas experiências, no início do século XXI, muitos cursos de licenciatura em História de universidades públicas passaram a investir na organização de laboratórios de ensino. Isto num contexto em que ocorreram avanços consideráveis na pesquisa em ensino de História e nas definições sobre as funções ocupadas pelas licenciaturas a partir das Resoluções 1 e 2/2002 do Conselho Nacional de Educação (CNE), que instituiu Diretrizes Curriculares Nacionais (DCNs) para a Formação de Professores de Educação Básica, em nível superior, curso de licenciatura, graduação plena (2002). ${ }^{5}$

Tais resoluções possibilitaram reflexões que redimensionaram as funções das licenciaturas em História na formação docente e na área de ensino de História dentro das graduações, comumente conhecidas pela forte presença da dicotomia entre ensino e pesquisa. Na esteira dessas discussões que perfizeram projetos pedagógicos de cursos (PPC's), novos lugares para a formação docente suscitaram debates sobre a condição de laboratórios na produção do conhecimento histórico.

Nesse contexto, nos anos de transição da UFMS para UFGD, como foi dito, o curso de História foi marcado por discussões voltadas para o fortalecimento da área de ensino e de estágio. Em meio a elas foi proposta a criação de um Laboratório de Ensino de História, considerando experiências de outras instituições de ensino superior, a ausência de um espaço onde graduandos pudessem estudar e fazer trabalhos de disciplinas, a falta de infraestrutura para professores da área de ensino para orientação de estagiários e elaboração de oficinas, a dificuldade de acesso dos estudantes de História a materiais didáticos, livros e revistas especializadas. Ao proporem a criação desse espaço, os professores objetivavam viabilizar aos alunos um lugar de estudos e de produção de conhecimento (OLIVEIRA, 2015; ZORZATO, 2015).

A questão que se colocava era como conquistar um espaço físico em meio às disputas que envolviam diferentes interesses dos cursos. Além disso, a

\footnotetext{
${ }^{5}$ Cf. <http://portal.mec.gov.br/seesp/arquivos/pdf/res1_2.pdf> . Resolução CNE/CP n. 1, de 18 de fevereiro de 2002. Consultado em abril de 2014.
} 
administração da UFMS tinha dificuldades de adequar um espaço com esta finalidade na iminência do desmembramento e da formação da UFGD. A situação começou a ganhar contornos mais nítidos diante da realização, em 2006, do "II Simpósio Internacional sobre Religiões, Religiosidades e Culturas" em Dourados (MS). Sob a organização de professores do curso de História, as despesas do evento foram quitadas e possibilitou a aquisição e doação de 17 computadores, 02 Impressoras, 01 Scanner, 01 Data Show e alguns filmes e DVDs. Essa movimentação forçou a administração central da UFMS a ceder uma sala para que o laboratório fosse instalado, inicialmente no prédio do Centro Pedagógico de Dourados (CPD), localizado na área central da cidade (OLIVEIRA, 2015).

A instalação do laboratório, em 2006, pode ser considerada uma das conquistas do corpo docente de História. Desse modo, as áreas de ensino e estágio marcavam posição no curso e na universidade. O espaço, num primeiro momento, parece ter provocado surpresas e estranhamento, já que a ideia de laboratório estava associada a utensílios de vidros com tamanhos e formatos variados, líquidos coloridos, fumaça e profissionais usando jalecos brancos, máscaras e luvas. Mas qual o significado de laboratório? Diante de tantas questões, a recorrência aos dicionários não foi casuística. No "Houaiss", laboratório era descrito como:

1. local provido de instalações, aparelhagem e produtos necessários a manipulações, exames e experiências efetuados no contexto de pesquisas científicas, de análises médicas, análises de materiais ou de ensino científico e técnico;

2. atividade que envolve observação, experimentação ou produção num campo de estudo (p.ex., o comportamento animal) ou a prática de determinada arte ou habilidade ou estudo; oficina;

3. local provido de instalações e equipamentos próprios para tratar filmes fotográficos ou cinematográficos;

4. parte de um forno de revérbero na qual se passam trocas de calor ou reações químicas (HOUAISS, 2007).

A concepção de um espaço de observação, experimentação, estudo e produção de conhecimento parecia se alinhar aos propósitos iniciais do Laboratório de Ensino de História, pois constituíam práticas que se esperavam para a formação docente. O professor do curso de História da UFGD, Osvaldo Zorzato tem a: 
...percepção de que o laboratório deva ser um espaço para congregar experiências, vivências e problematizar temáticas específicas sobre Aprender/Ensinar/Aprender História nas múltiplas dimensões em que atua este profissional. De tal maneira que não se sinta constrangido em se identificar como professor de História, escondendo-se na condição de historiador (ZORZATO, 2015)

A fala ilustra o debate que se travava em torno da identidade do professor de História. O desafio era mostrar aos discentes que estavam sendo formados para serem professores e o objetivo era dar condições para atuar como "professor de história produtor de saberes, capaz de assumir o ensino como descoberta, investigação, reflexão e produção" (FONSECA, 2003, p. 62).

Para Benícia Couto de Oliveira (2015), professora envolvida com a formação e organização do Laboratório de Ensino de História, os docentes do curso almejavam um espaço para os acadêmicos fazerem "leituras, pesquisas, (...) material didático para os estágios e demais atividades pedagógicas", trocarem "experiências", construírem "conhecimento e, paulatinamente, aprendizagem".

Trocas de experiências e aprendizagem, num primeiro momento, sintetizavam os objetivos do lugar na formação docente. Podemos dizer que em lugares como este se produz conhecimento histórico a partir de discussões que relevam a teoria, a prática, o ensino e a pesquisa como dimensões para a formação do professor-pesquisador. Ao mesmo tempo, de acordo com a concepção e organicidade dada ao espaço, por meio de atividades de ensinopesquisa e de estágio docente, tornou-se possível vislumbrar ações para aproximar universidade e escolas de educação básica.

Ainda, segundo a professora, a criação do Laboratório de Ensino de História foi bem recebida pelos discentes, pois eles passaram a ter uma sala que dava condições de estudos e pesquisas, tendo a internet como importante ferramenta. Naquele momento, muitos estudantes não tinham acesso a microcomputadores e a rede virtual. Assim, o lugar tornou-se referência no cotidiano de estudo e socialização dos acadêmicos, além de espaço de reflexão, o que gerou debates sobre o uso e as implicações de novas tecnologias de informação e comunicação nas práticas de ensino de História (OLIVEIRA, 2015). 


\section{Um lugar para as práticas}

Em meio a tantas possibilidades para elucidar o "lugar", enquanto tratávamos da elaboração deste artigo, noticiários locais apresentavam o cenário em que vivem indígenas no Estado de Mato Grosso do Sul. Expropriação de terras, alcoolismo, drogas e variados tipos de violência que resultam em assassinatos, tornaram-se retratos cotidianos de homens, mulheres e crianças indígenas. Neste contexto, a UFGD manteve e implantou cursos na área de ciências humanas em que se tornaram representativos projetos de pesquisa, ensino e extensão que lidam com temáticas dos movimentos sociais rurais e urbanos.

A construção de um campo de ensino e pesquisa, voltado para temáticas sociais, envolveu docentes com questões políticas que muito diziam sobre as práticas do profissional de História num lugar de tensões sociais, como a região da Grande Dourados. O alinhamento do curso a questões políticas e sociais possibilitou na década de 1990, ainda UFMS, a criação da História Indígena como componente curricular na graduação e como linha de pesquisa no programa de pós-graduação, em nível de mestrado. Ações deste gênero são representativas da postura política adotada pelos docentes do curso, muitos envolvidos com o projeto de implantação da UFGD e com os debates sobre os movimentos sociais, em especial a questão indígena, antes mesmo da aprovação da Lei n. 11.645/08. 6 Afinal, não era possível negligenciar uma dura realidade que bate às portas diariamente com a recorrente frase dita por crianças indígenas: "tem pão velho?".7

Sem perder de vista esse posicionamento e frente aos debates a respeito das relações etnicorraciais e ensino de História, em 2008, a partir das discussões

6 Cf. <http://www.planalto.gov.br/ccivil_03/_ato2007-2010/2008/lei/l11645.htm>. A Lei n. 11.645, de 10 de março de 2008 alterou a Lei n. 9.394, de 20 de dezembro de 1996, modificada pela Lei n. 10.639, de 9 de janeiro de 2003, que estabeleceu as diretrizes e base da educação nacional, para incluir no currículo oficial da rede de ensino a obrigatoriedade da temática "História e Cultura Afro-brasileira e Indígena".

7 É comum na cidade de Dourados, crianças indígenas, com suas mães e irmãos ou sozinhas, caminharem pela cidade e pararem nas residências para pedir alimentos, água para beber, roupas ou calçados, tendo como expressão inicial de seu pedido: "tem pão velho?" 
para a reformulação do PPC História ${ }^{8}$, foi introduzida na matriz curricular a disciplina obrigatória de História da África e rediscutido o papel do Laboratório de Ensino de História. Em 2009, foi criado o Laboratório de Ensino de História Indígena e publicado o dossiê "Ensino de História" na Fronteiras: Revista do Programa de Pós-Graduação em História da UFGD. Além disso, foram abertos concursos docentes para as áreas de Ensino de História e Estágio Supervisionado. Essas ações, aparentemente isoladas e esporádicas, fazem parte do contexto das discussões que fortaleceram as áreas específicas da licenciatura em História, impulsionadas pelas Resoluções 1 e 2/2002 do CNE, e dialogam com os estudos sobre a formação docente das últimas décadas, que acenam para o reconhecimento da heterogeneidade e diversidade cultural.

No campo da História, os processos de formação de professores em cursos universitários, amparados na legislação produzida no início do século XXI, apontaram para a superação de distâncias entre as disciplinas consideradas básicas da área, as específicas da licenciatura e a dimensão prática da formação docente em História nos PPC's. A prática deveria permear toda a licenciatura, privilegiando a formação do professor não apenas nas disciplinas pedagógicas, mas nas que constituíssem os componentes curriculares, considerando uma dimensão prática ao longo do curso. (FONSECA e SILVA, 2010, p. 36).

Vale observar que a forma encontrada pelo corpo docente para atender as Diretrizes, ainda no período da UFMS, foi diminuir e excluir as cargas horárias de algumas disciplinas básicas do curso para inserir um maior número das relacionadas às práticas de ensino, que serão mencionadas a seguir. Esses componentes curriculares foram ministrados por todos os professores e, ainda que com resistência de um ou outro, a estrutura representava avanços e investimentos no ensino de História. A divisão dos Estágios Supervisionados em I e II destinava-se, respectivamente, a atividades de observação e de regência nas escolas de educação básica, ficando sob a responsabilidade de até dois professores (PPC HISTÓRIA, 2008).

O conceito de prática de ensino presente nessa estrutura estava relacionado ao desenvolvimento de habilidades necessárias à prática docente, ao

\footnotetext{
8 Maiores informações no item 3.
} 
treinamento em situações experimentais, dentre as quais, a realização de "miniaulas". Segundo Pimenta,

\begin{abstract}
Uma decorrência de tal concepção de prática é o microensino, que dispensa situações de regência de classe na escola básica, uma vez que a atividade docente precisa ser cientificamente estudada, criando-se situações experimentais para desenvolver habilidades em situações controladas. (PIMENTA apud CAIMI, 2008, p. 88).
\end{abstract}

Essa concepção tem seus limites, pois a única variável controlável é o professor, o que não representa a diversidade do controle do contexto escolar, tampouco a complexidade do processo pedagógico (CAIMI, 2008, p. 88). Apesar dessa limitação, com a qual concordamos, acreditamos que o planejamento e realização de miniaulas pelos alunos, ainda que para colegas e professores, contribuem para, ao chegarem ao Estágio Supervisionado, colocarem em prática alguns dos recursos ou propostas experimentadas anteriormente, construindo um comportamento de lidar e falar em público.

Quanto ao Laboratório, a organização de normas para o seu funcionamento nos oferece uma síntese das pretensões que os docentes do curso tinham sobre o lugar. Os propósitos iniciais eram evidentes com a denominação Laboratório de Estudos e Pesquisa em Ensino de História (LEPEH), um lugar "destinado às atividades de ensino do curso de graduação em História" (LEPEH, 2006, p. 1). As atividades de extensão e pesquisa eram permitidas, desde que fossem relacionadas ao ensino de História. Num sentido geral, ficou definido que o laboratório tinha como objetivo apoiar docentes na elaboração de materiais didáticos para atividades didático-pedagógicas na universidade e nas escolas de educação básica, onde fosse realizado o Estágio Supervisionado (LEPEH, 2006, p. 1).

Esta tendência que focou mais o ensino é percebida através de encaminhamentos de documentos internos na Faculdade de Ciências Humanas (FCH) e UFGD. A coordenação do laboratório, assumida pela professora Benícia Couto de Oliveira, desde 2006, passou a se referir ao lugar como Laboratório de Ensino de História, constando a sigla LABhis em pastas de acompanhamento de monitores em 2008. Em documentação que tratou de materiais de consumo, 
reparos e aquisições de equipamentos, reservas para uso, monitoria voluntária, bolsa monitoria, equipes de trabalho, a denominação e a sigla ganharam forças perante a proposta inicial de LEPEH. (LABhis, 2008).

O atendimento prioritário dado às disciplinas da área de ensino demonstra que o laboratório poderia ocupar uma função de articulação de diferentes projetos de ensino e pesquisa, diante de um significativo número de disciplinas que tratavam das práticas no curso de História: Oficinas de História, Prática de Ensino de História, Prática de Ensino de História Geral, Prática de Ensino de História da América, Prática de Ensino de História do Brasil, Prática de Ensino de História Regional, Pesquisa e Ensino de História, Estágio Supervisionado I e II(LEPEH, 2006, p. 2).

As aulas de práticas e as orientações de Estágio Supervisionado tinham o Laboratório de Ensino de História como espaço de realização. A estrutura curricular, amparada nas DCNs para os Cursos de História (2002) ${ }^{9}$ e nas DCNs para a Formação de Professores da Educação Básica, em nível superior, curso de licenciatura (2002), reforçou a necessidade da articulação entre ensino e pesquisa, definindo que as práticas não poderiam ficar reduzidas a um espaço isolado e o Estágio Supervisionado desvinculado das demais atividades do curso.

Dentre os componentes curriculares relativos às práticas, "Oficinas de História" teve o Laboratório de Ensino de História como lugar privilegiado para seu desenvolvimento. A disciplina tinha como objetivo a elaboração de materiais didáticos alternativos, a discussão do uso de novas tecnologias, das linguagens e dos meios de comunicações no ensino de História. Os discentes organizavam aulas por meio de slides, usos de filmes, de músicas e elaboração de textos didáticos sob a supervisão de um professor do curso (PPC História, 2008).

As estratégias de aulas simuladas a partir do contato dos licenciandos com novas tecnologias da informação e comunicação, muito contribuíram para a formação nestes anos. A questão que se colocava era como lidar com tantas novidades e suportes efêmeros, alguns muito menos longevos do que os anos necessários para a formação em História.

9 Cf. <http://portal.mec.gov.br/cne/arquivos/pdf/CES132002.pdf>. Resolução CNE/CES n. 13, de 13 de março de 2002. 
Jornais, rádio, televisão, cinema, vídeos, fotografias, informática, internet, hipertextos, web conferências, CD-ROM e DVD, tornaram-se ferramentas para as aulas de História, mas trouxeram uma série de implicações na formação docente. Nesses anos, diversos artigos e capítulos de livros foram publicados a respeito do uso de equipamentos e de novas linguagens na sala de aula, tidas como alternativas ao livro didático de História e às aulas expositivas. Como apontou Ferreira (2004, p. 77), essas tecnologias vieram para ficar e o grande problema era saber a função e estratégias desses meios nas atividades educativas.

Com a criação da UFGD, o curso de História foi transferido do CPD para a cidade universitária inaugurada em 2007, distante da área central de Dourados (MS). O Laboratório de Ensino de História, ao integrar a Faculdade de Ciências Humanas (FCH), ganhou sala que abrigou os computadores e materiais portáteis que compunham o espaço organizado no CPD.

Após a mudança foi constatada uma baixa na frequência dos discentes no laboratório (OLIVEIRA, 2015). Num primeiro momento, a explicação usada para a situação foi a distância da universidade e o número considerável de alunos residentes em outros municípios. Mas outras razões podem explicar a diminuição de frequentadores, como a gradativa condição obsoleta dos computadores frente à popularização e expansão dos computadores portáteis. Acrescentamos, ainda, que o esvaziamento do laboratório por parte dos acadêmicos ficou mais acentuado quando a cidade universitária passou a contar com acesso livre a internet. $\mathrm{Na}$ contramão do esvaziamento de estudantes de História em decorrência da transferência do curso, um gradativo aumento da procura do espaço por estudantes e professores de novos cursos da $\mathrm{FCH}$ construiu uma imagem de que o Laboratório de Ensino de História era uma sala de informática.

Diante desse panorama, a partir de 2008 a movimentação no laboratório passou a ocorrer basicamente no período noturno durante as aulas de práticas de ensino ou orientações de estágios. Além disso, perante as novas demandas que se faziam na configuração dos novos cursos, o espaço foi dividido, por alguns anos, como laboratório de ensino dos cursos de Ciências Sociais e de Psicologia da UFGD. 
Apesar das razões mencionadas, poderíamos questionar se o modelo inicial do laboratório, com muitos computadores, ainda contemplava os objetivos da licenciatura em História. O que estava em jogo era a evanescência dos suportes tecnológicos no ensino de História em meio aos avanços da tecnologia do mercado de computadores.

Esta questão foi tratada por historiadores. Os anos que separam as publicações "Domínios da História" (1997) e "Novos Domínios da História" (2012) são o retrato do paradoxo entre o tempo da universidade e o tempo do mercado de informática. Figueiredo (1997) alertou para o debate que era preciso fazer sobre o uso do computador na História. Anos depois, Tavares (2012) chamou atenção para a crescente produção de equipamentos e programas que visam atender a demanda do mercado. Apesar de uma multidão de "excluídos digitais" que não acessam computadores e as redes virtuais, neste processo, mudaram-se os usos, costumes e práticas, especialmente entre os mais jovens, que acessam informações e se comunicam mediante diferentes suportes. $O$ uso dos computadores pelos alunos nas salas de aula pode criar condições de aprendizado, mas os professores também precisam ser instruídos para o uso destas ferramentas a fim de superar medos e desconfianças com as tecnologias. (TAVARES, 2012, p. 313).

Alguns anos após a instalação de computadores, o paradoxo parecia se refletir no Laboratório de Ensino de História. De um lado, a diminuição de frequentadores demonstrava não apenas os problemas gerados pela transferência para a cidade universitária, mas também o acesso de muitos acadêmicos a computadores portáteis e telefonia móvel. Em contrassenso, o curso apresentava casos de alunos que nunca tinham trabalhado ou desenvolvido qualquer atividade com computadores.

\section{Articulando lugares}

A expansão da UFGD teve relação com o Programa de Apoio a Planos de Reestruturação e Expansão das Universidades Federais (REUNI) aprovado em 
2008 pelo governo federal. Seu objetivo era "criar condições para a ampliação do acesso e permanência na educação superior, em nível de graduação, pelo melhor aproveitamento da estrutura física e de recursos humanos existentes nas universidades federais". ${ }^{10}$ Por causa desse programa e dos recursos dele obtidos, concursos docentes para diversas áreas foram abertos, cursos e laboratórios foram criados, prédios concluídos, PPCs reformulados e o número de vagas nas graduações ampliadas.

As mudanças afetaram as cargas horárias dos cursos e algumas disciplinas tiveram nova diminuição de suas horas ou foram excluídas. No curso de História, os inúmeros componentes curriculares de práticas de ensino, mencionados anteriormente, se transformaram em três disciplinas: Ensino de História I, II e III, com cargas horárias superiores em relação às anteriores. (PPC HISTÓRIA, 2008) Elas passaram a ser ministradas desde o início do curso, tendo como objetivo a inserção dos discentes em temáticas mais específicas da formação docente, que abrangiam a trajetória do ensino História no Brasil, as relações etnicorraciais, patrimônio cultural material e imaterial, lugares de memória e o uso de diferentes tecnologias e tipologias documentais. ${ }^{11}$

Os Estágios Supervisionados I e II tiveram acrescentado o III, isto porque os professores responsáveis consideraram que, para melhor aproveitamento dos discentes, era importante manter o estágio I para a observação e dividir as regências nos ensinos fundamental e médio, respectivamente, nos estágios II e III. Essa estrutura levava em consideração as etapas de formação do adolescente e suas habilidades, aspectos vistos como relevantes para que o estagiário também soubesse lidar com cada situação, faixa etária e encaminhamento das aulas.

Como se vê, mais uma vez foi enfatizada a necessidade de não se perder de vista a articulação entre ensino e pesquisa, o fortalecimento dos estágios e a inclusão de temas que fossem pensados no âmbito do ensino de História. Com a inserção desses temas nas disciplinas Ensino de História I, II e III, o projeto do

10 Cf. <http://www.planalto.gov.br/ccivil_03/_Ato2007-2010/2007/Decreto/D6096.htm>.

${ }^{11}$ Essas perspectivas tinham como base os Parâmetros Curriculares Nacionais (PCN), a Lei n. 11.645, de 10 de março de 2008 e o Decreto n. 3.551, de 4 de agosto de 2000, que instituiu o Registro de Bens Culturais de Natureza Imaterial que constituem patrimônio cultural brasileiro e criou o Programa Nacional do Patrimônio Imaterial. 
curso pretendia demonstrar aos discentes as várias possibilidades de temáticas a serem incorporadas no ensino e pesquisa articulando os componentes curriculares básicos com os específicos da licenciatura em História (PPC HISTÓRIA, 2008).

Defendia-se, ainda, que a formação docente poderia ocorrer em outros espaços que não apenas o da escola. Museus, arquivos, sindicatos de professores e demais lugares de memória deveriam ser mais valorizados no processo de ensino e aprendizagem. Esta articulação que se pretendia do futuro professorpesquisador de História com outros lugares, possibilitou ampliar o uso do Laboratório de Ensino de História. Assim, projetos de ensino e pesquisa foram integrados ao espaço do Laboratório através de reuniões, orientações e atividades.

Contudo, as aulas de prática de ensino e as orientações de estágio não pareciam ser suficientes para demarcar o papel do laboratório na recém-criada universidade. No contexto de adequação e divisão das novas instalações da UFGD, o uso do LABhis foi pauta de inúmeras reuniões da Comissão do curso de História, que após anos das primeiras discussões sobre ensino e estágio ainda reafirmava a necessidade de fortalecimento da área.

Diante da disputa por espaços no interior da $\mathrm{FCH}$ em decorrência do aumento do número de cursos, professores e vagas na graduação, e da necessidade de utilização do espaço, o Laboratório de Ensino de História passou a abrigar, além das atividades de estágio, de prática e de pesquisa em ensino, reuniões da Comissão do curso de História, de grupos de orientação do Programa Institucional de Bolsas de Iniciação Científica (PIBIC), do Programa de Bolsas de Licenciatura (PROLICEN), do Programa de Pós-Graduação em História (PPGH) e do Programa Institucional de Bolsas de Iniciação à Docência (PIBID).

Iniciativa tomada desde 2011, a realização das reuniões da Comissão do curso de História no LABhis tornou-se uma forma de territorialização do espaço. Tendo em vista a definição de laboratório de ensino apresentada anteriormente, como lugar de aprendizagem, de trocas de experiências e de produção do conhecimento, acrescentamos, que o laboratório tem se tornado o lócus por 
excelência das discussões pedagógicas e políticas que norteiam o curso de História da UFGD.

Da mesma maneira, a coordenação naquela circunstância acreditava que era preciso mudar o layout da sala e inserir elementos que remetessem ao universo escolar, a pesquisa e ao ensino de História e a realidade dos discentes, como estratégia para mudar percepções de que se tratava de sala de informática ou de que o laboratório não era do curso. Não bastasse a ausência dos discentes, as paredes e a aridez do ambiente poderiam passar a sensação de aridez nas ações, evidenciando a não vivência no lugar.

Nesta perspectiva era necessário ocupar o lugar com diferentes atividades. Um exemplo foi o Programa de Bolsas de Licenciatura (PROLICEN), desenvolvido na UFGD com objetivos de incentivar a participação de discentes, através de concessão de bolsas, em projetos de pesquisa, que investissem na qualidade dos cursos, na permanência e conclusão pelos alunos das diversas licenciaturas. Da mesma maneira, o programa visava propiciar uma efetiva articulação dos cursos de Licenciatura com os ensinos fundamental e médio e uma formação docente de qualidade. ${ }^{12}$

Entre os anos de 2007 e 2012, sete projetos PROLICENs foram desenvolvidos por docentes e discentes do curso de História. Apesar de seus vínculos com o Laboratório de Ensino de História terem sido pouco divulgados, os projetos focaram a relação com o ensino. O LABhis foi lugar para discussões dos textos, partilhas de experiências e orientações dos projetos desenvolvidos por professores que trabalhavam com a área de ensino e estágio. Todos eles tinham como horizonte o fortalecimento da área de ensino.

Os projetos PROLICENs tiveram como arcabouço o ensino de História através de temáticas como informática, livro didático, cultura afro-brasileira, representações indígenas e africanas, mulheres, desempenho de alunos e escolas públicas (BENFICA, 2007; JUSTINO, 2010; SILVA e SOUZA, 2008; FERNANDES, 2008; SANTOS, 2010; PARRA, 2012; RAMOS e POSSADAGUA, 2008). Dentre os principais resultados oriundos desses projetos, destacamos as dissertações de

${ }^{12}$ A respeito do PROLICEN ver página http://portal.ufgd.edu.br/coordenadoria/cograd/prolicen 
mestrado defendidas por bolsistas PROLICENs que ingressaram no Programa de Pós-Graduação em História (BENFICA, 2011; SOUZA, 2014).

Além do PROLICEN, acrescentamos outros projetos de pesquisa que, necessariamente, não estavam vinculados ao ensino, mas ao laboratório através de suas concepções de formação de professor-pesquisador. Atividades como reuniões, orientações, oficinas de paleografia, discussões de projetos, foram desenvolvidas no LABhis. Muitas destas ações contaram com a participação de discentes da graduação e da pós-graduação. ${ }^{13}$

Nos últimos anos, abrangendo atividades mais específicas do ensino, o Programa Institucional de Bolsas de Iniciação à Docência (PIBID), por valorizar a formação inicial de professores tornou-se um importante programa para o desenvolvimento de atividades junto ao LABhis e para a promoção de debates sobre a condição do curso de Licenciatura em História da UFGD na formação docente. Introduzido na UFGD no ano de 2008 (ARANDA, 2011, p. 3), o PIBID contribuiu para o envolvimento de docentes do curso de História com projetos de maior duração junto às escolas públicas do município de Dourados (MS).

O PIBID/História passou a integrar o PIBID/UFGD em 2009, com o subprojeto "Ensino de História e formação de professores: o ensino pela arte". (RAMOS, 2008). Como consta em seu planejamento, os objetivos do PIBID/História eram "elevar a qualidade das ações acadêmicas voltadas à formação inicial de professores de curso de Licenciatura em História, articulando a formação de docentes de História à realidade educacional de Dourados, visando melhorar a educação básica" (RAMOS, 2008).

Em 2011 teve início o PIBID/História "Ensino de História e formação de professores: ensinando com recursos audiovisuais" (OLIVEIRA, 2011), tendo "por objetivo a aplicação de recursos audiovisuais e multimídia no processo ensinoaprendizagem de História, nos ensinos fundamental e médio". A proposta era levar ferramentas que pudessem agregar conhecimento histórico ao ambiente escolar de educação básica (OLIVEIRA, 2011).

13 Referimo-nos ao projeto de pesquisa "Nas rotas do comércio: Governadores e clérigos em uma região fronteira - mineira da América portuguesa (1740-1796)", financiado pelo Edital Universal/2009, desenvolvido entre os anos de 2009 e 2013, coordenado por Nauk Maria de Jesus. 
Em 2012 foi iniciado o subprojeto "Formação e prática docente no ensino fundamental: incorporação de temáticas propostas nos Parâmetros Curriculares Nacionais ao ensino de História" (SILVA, 2012). Com a aprovação junto a Coordenação de Aperfeiçoamento de Pessoal de Nível Superior (CAPES), o PIBID/História passou a contar com duas ações simultâneas, envolvendo quatro escolas estaduais de Dourados (MS). O foco do subprojeto era a interdisciplinaridade para discutir diversos temas transversais mediante a organização de oficinas que articulavam comunidade escolar, PIBID e UFGD (SILVA, 2012).

A finalização dos dois subprojetos em 2013 foi seguida com a aprovação do subprojeto "Representações no Ensino de História: articulações de materiais didáticos e usos de linguagens no Ensino Médio" (OLIVEIRA e PERLI, 2013). Este subprojeto se constituiu a partir de reflexões desenvolvidas no LABhis, que articulou, a partir de 2012, Oficinas de Ensino de História Contemporânea, a elaboração de sequências didáticas na disciplina de Ensino de História II e as expectativas e considerações sobre a prática docente no Estágio Supervisionado em História III, com atuação no Ensino Médio.

Tais reflexões apontaram que o livro didático ainda ocupava papel predominante nas práticas docentes de História, conforme descreveram alunos estagiários da Licenciatura em História nas escolas da rede pública de Dourados (MS). A premissa do subprojeto não se diferenciava dos anteriores, pois defendia o contato mais efetivo com a cultura escolar, a partir da articulação entre universidade e escola, dimensionada pela supervisão de professores das escolas participantes, por leituras e seminários desenvolvidos pelo LABhis. O que se pretendia aprofundar era o enfoque dado aos usos de diferentes materiais didáticos e linguagens no ensino de História, considerando perspectivas múltiplas advindas de lugares em que trabalhavam quatro professores de educação básica, denominados de supervisores do PIBID/História (OLIVEIRA; PERLI, 2014).

A articulação de diferentes linguagens no desenvolvimento de saberes históricos no ensino médio ganhou relevância nas últimas décadas ante a expansão de instrumentos de comunicação e da difusão de representações que legitimam atores e grupos sociais no contexto histórico. As "representações de 
mundo social" (CHARTIER, 2002) são entendidas como integrantes da realidade social, formas de expressão de diferentes grupos sociais que produzem e difundem discursos e aparatos de memória através de mecanismos de comunicação - como arte, impressos, rádios, audiovisuais, internet, músicas, museus e variados lugares de memória - que redefiniram o papel da documentação no campo historiográfico e as metodologias de ensino de História.

Como se vê, nesses anos, o PIBID/História, além de inserir estudantes da licenciatura em ambientes escolares de educação básica ao longo do curso, abriu perspectivas de reflexão sobre a formação docente, considerando inúmeras experiências e a diversidade social e cultural que as escolas parceiras do projeto poderiam oferecer. Neste sentido, construiu-se uma expectativa de que a relação entre bolsistas e professores da educação básica em diferentes ambientes escolares pode contribuir para a formação docente dos envolvidos no subprojeto e para o debate das ações desenvolvidas pelo curso de licenciatura em História, tendo o LABhis a função de articular práticas, difundir e a socializar experiências didáticas.

\section{Repensando o lugar}

Nos últimos anos, além de encontros e atividades de ensino e orientação, o LABhis objetiva a produção, sistematização e disponibilização de informações e materiais que envolvem a iniciação docente. Dentre várias ações, podemos mencionar o projeto de revitalização do LABhis, a organização de Grupos de Trabalho (GTs), a inserção no PPC-História 2015 da disciplina Relatório de Formação Docente e a configuração de um campo de investigação de Estágio Supervisionado, que propõe outros tipos de articulações entre as escolas de educação básica e o laboratório. 
Nesta perspectiva, o projeto "Lugares de história, registros de memória: revitalização do LABhis/UFGD" conseguiu auxílio financeiro da Fundação de Apoio e Desenvolvimento do Ensino, Ciência e Tecnologia do Mato Grosso do Sul (Fundect). O projeto tem como objetivo revitalizar e instrumentalizar o LABhis, fomentando estudos acerca do Ensino de História e suas diversas abordagens e contribuindo para a formação docente em História. A proposta sugere ao LABhis a condição de espaço articulador entre as atividades de formação docente do curso de licenciatura em História, da área de Ensino de História, do campo de investigação de Estágio Supervisionado em História, do Programa de Bolsas de Iniciação à Docência (PIBID/História), considerando as múltiplas relações com escolas de educação básica do município de Dourados (MS). O projeto ampara-se na necessidade de articulação das diversas etapas formativas do profissional de História, constituídas por práticas de leitura e escrita, debates, reflexões, sistematização de fontes históricas, pesquisas e elaboração de ferramentas que possibilitem a socialização do conhecimento histórico (PINTO, 2014).

Além disso, a partir de 2014, através do PIBID/História foram organizados GTs compostos por bolsistas para dar suporte ao subprojeto nas escolas participantes e às ações vinculadas ao LABhis. Assim, os GTs "Patrimônio, Publicidade, Página do LABhis, Oficinas, LAB e-his, Banco de Dados PIBID e Acervo Docência" realizam encontros semanais com atividades específicas que visam a sistematização de atividades de ensino e pesquisa.

Dentre os GTs, o "Acervo Docência" tornou-se um projeto focado para novas demandas da licenciatura definidas no PPC História-2015. Através do Núcleo Docente Estruturante (NDE) tornou-se consenso criar mecanismos norteadores para os acadêmicos e para a análise contínua do curso por parte de seus docentes. Uma das propostas consistiu na organização de disciplinas para constituir um mosaico de atividades que contribua para analisar a trajetória do estudante ao longo da licenciatura, considerando diferentes ações para integrar um trabalho sistematizado de conclusão de curso. Neste sentido, configurou-se o Relatório de Formação Docente, equivalente ao Trabalho de Conclusão de Curso (TCC) de licenciatura. 
O Relatório de Formação Docente foi proposto como um instrumento de arregimentação de atividades de ensino, pesquisa e extensão desenvolvidas pelos acadêmicos no decorrer do curso de licenciatura em História da UFGD, compondo uma espécie de "dossiê" de cada estudante com a finalidade de apresentar suas diversas experiências e considerações sobre a formação docente.

Além de se analisar a formação de cada estudante em vias de conclusão do curso, a proposta do Relatório de Formação Docente caminha no sentido de se produzir informações para análises sobre a organicidade, atuação e contribuição da licenciatura na formação de professores de História. Trata-se de um trabalho para avaliar implicações, limites, condições e produções do curso, como forma de tecer olhares críticos advindos de diferentes trajetórias e que se confluem na necessidade constante de repensar os lugares da formação docente.

Ocupando função na composição do Relatório de Formação Docente de cada acadêmico, o Acervo Docência é o banco de dados do LABhis cujo objetivo é armazenar, sistematizar e disponibilizar produções nas áreas de Estágio Supervisionado e Ensino de História para subsidiar pesquisas que tratam da formação docente. Organizado a partir de 2013, o Acervo Docência propõe subsidiar pesquisas que tratam da formação docente oferecendo diversos materiais produzidos e desenvolvidos no curso de licenciatura em História, como aulas simuladas, memoriais de estudantes, fontes midiáticas, experiências e projetos de ensino de História, relatórios de observação e regência dos Estágios Supervisionados e Relatórios de Formação Docente (COELHO; PERLI, 2015).

Mais recentemente, o espaço físico do LABhis vem passando por modificações para dar suporte aos novos projetos. Num sentido geral, a proposta manteve o espaço de reuniões, orientações e atividades de ensino e, por meio de divisória, definiu uma sala administrativa para coordenação, trabalhos técnicos e de sistematização dos projetos abrangidos pelo laboratório.

Como se vê, os últimos debates sobre o lugar ocupado pelo LABhis na licenciatura em História da UFGD reafirmam um espaço para o desenvolvimento de projetos de ensino e pesquisa que problematizam o campo teórico e de atuação do professor de História, servindo de arcabouço para diferentes projetos 
e atividades das áreas do conhecimento histórico que propõem diálogos com o ensino de História.

\section{Considerações finais}

A organização do Laboratório de Ensino de História moldou uma percepção de que o lugar é uma construção coletiva. Além da condição física, seu significado tem forte conotação política, fazendo com que a concepção de laboratório seja menos a de um espaço rígido e mais de um espaço em construção que se faz com articulações e interesses do curso. Esta questão nos remete a dinâmica que diferentes lugares de produção de saberes ocupam na formação docente em História, o que ainda requer ajustes para repensar o lugar enquanto estratégia do "fazer História".

Ao significado de lugar de aprendizagem, de trocas de experiências e de produção do conhecimento, não se pode desvincular o fortalecimento da concepção de que o LABhis é uma construção política e coletiva dos docentes do curso de História, iniciada nos idos de 2002. Além disso, ressaltamos que ele tem se tornado o lócus por excelência das discussões pedagógicas e políticas que norteiam o curso de História da UFGD. A postura dos docentes articulada às lutas e tensões pela consolidação de um espaço que desse suporte ao ensino e a pesquisa em História, construiu um sentido de lugar que reflete a condição política do próprio curso.

Como evidenciamos, é pertinente pensar o laboratório de ensino de História articulada à trajetória do próprio curso de História da UFGD e os momentos de sua criação, transição de uma universidade para outra e seu processo de consolidação. Nesse período, a própria concepção de laboratório de ensino ganhou novos significados a partir das práticas e discussões feitas pelo corpo docente.

Deste modo, lugares que se fazem a partir de várias experiências e perspectivas não podem ser relegados na formação docente em História. Num mundo em que a complexidade das relações sociais se faz num jogo de 
elaboração e difusão de representações de grupos que buscam legitimidade e visibilidade na História, a construção de um Laboratório de Ensino de História pode ser considerada atividade simplória para alguns. No entanto, a produção do lugar decorre da configuração de tantos outros, que não são mais ou menos importantes, mas se complementam e constituem a multiplicidade de ações na produção do conhecimento histórico.

\section{Referências}

ARANDA, M. A. de M. O PIBID na UFGD: ação, reflexão, ação. ANAIS DO XXV SIMPÓSIO BRASILEIRO DE POLÍTICA E ADMINISTRAÇÃO DA EDUCAÇÃO. ANPAE: São Paulo, 2011.

BENFICA. T. O ensino de História: contribuições da informática à prática pedagógica. Relatório final de PROLICEN com orientação de OLIVEIRA, Benícia Couto de. Dourados, UFGD, 2007.

Perfil do professor de História: representações e identidades em escolas públicas de Dourados. 2011. 150f. Dissertação (Mestrado em História) Universidade Federal de Dourados, Dourados, 2011.

CAIMI, F. E. Aprendendo a ser professor de história. Passo Fundo: Ed. Universidade de Passo Fundo, 2008.

CERTEAU, M. de. A escrita da história. 2 ed. Rio de janeiro: Forense Universitária, 2000.

CHARTIER, R. A história cultural: entre práticas e representações. 2 ed. Lisboa: Difel, 2002.

COELHO, F.; PERLI, F. (coord.). Projeto Acervo Docência. LABhis/FCH/UFGD: Dourados, MS, 2015.

FERNANDES, J. Representações sobre o indígena na Escola Estadual Menodora Fialho de Figueiredo em Dourados. Relatório PROLICEN com orientação de JESUS, Nauk Maria de. Dourados, UFGD, 2009.

FERREIRA, C. A. L. Ensino de história: reflexões e novas perspectivas. Salvador: Quarteto, 2004.

FIGUEIREDO, L. R. História e informática: o uso do computador. In. CARDOSO, Ciro Flamarion; VAINFAS, Ronaldo (orgs.). Domínios da História: ensaios de teoria e metodologia. 5 ed. Rio de Janeiro: Campus, 1997, p. 419-439. 
FONSECA, S. G. Didática e prática de ensino de História: experiências, reflexões e aprendizados. 7 ed. Campinas: Papirus, 2003.

HOUAISS, A. Dicionário da Língua Portuguesa. Online, 2007.

JESUS, N. M. de. Livros didáticos de História regional: saberes, representações e regionalismos. Projeto de Pesquisa em Ensino -PROLICEN - cadastrado na UFGD. Dourados, UFGD, 2008.

. Mato Grosso colonial: Temas e textos para o ensino de História. Projeto de Pesquisa em Ensino cadastrado na UFGD. Dourados, UFGD, 2010.

JUSTINO, L. M. O uso do livro didático: um estudo de caso. Relatório final do PROLICEN com orientação de OLIVEIRA, Benícia Couto de. Dourados, UFGD, 2008.

KARNAL, L. (Org.). História na sala de aula: conceitos, práticas e propostas. 5 ed. São Paulo: Contexto, 2008.

MARIN, M. F. Relação teoria e prática na formação de professores de História: experiências de laboratórios de ensino no Brasil e da Associação de Professores de História em Portugal (1980 - 2010). 2013. 292f. Tese (Doutorado em Educação) - Universidade Federal do Paraná, Curitiba, 2013.

OLIVEIRA, B. C. de (Coord.). Ensino de História e formação de professores: ensinando com recursos audiovisuais. Subprojetos da Licenciatura História PIBID/CAPES/UFGD. FCH/UFGD: Dourados, MS, 2011.

; PERLI, F. (coord.). Representações no Ensino de História: articulações de materiais didáticos e usos de linguagens no Ensino Médio. Subprojeto da Licenciatura História - PIBID/CAPES/UFGD. FCH/UFGD: Dourados, MS, 2014.

PARRA, S. A. Livres, forras e cativas em Mato Grosso Colonial: As mulheres no ensino de História. Relatório final PROLICEN com orientação de JESUS, Nauk Maria de. Dourados, UFGD, 2012.

PINTO, A. A. (Coord.). Lugares de história, registros de memória: revitalização do Laboratório de Ensino de História (LABhis) da Universidade Federal da Grande Dourados. Projeto aprovado - Chamada Fundect/Cnpq n. 14/2014 - PPP - MS, 2014.

POSSADAGUA, L. ENEM: Estudo do desempenho dos alunos de escolas públicas de Dourados, MS nas provas de História de 2004 a 2007. Relatório final PROLICEN com orientação de RAMOS, Antonio Dari. Dourados, UFGD, 2009

RAMOS, A. D. (Coord.). Ensino de História e Formação de professores: o ensino pela arte. Subprojeto da Licenciatura História - PIBID/CAPES/FNDE/UFGD. FCH/UFGD: Dourados, MS, 2008. 
SANTOS, R. M. dos. A Representação dos Africanos e afrodescendentes nos livros didáticos. Relatório PROLICEN sob orientação de JESUS, Nauk Maria de, UFGD, Dourados, 2010.

SILVA, E. J. da (coord.). Formação e prática docente no ensino fundamental: incorporação de temáticas propostas nos Parâmetros Curriculares Nacionais ao ensino de História. Subprojetos da Licenciatura História - PIBID/CAPES/UFGD. FCH/UFGD: Dourados, 2012.

SILVA, M.; FONSECA, S. G. Ensinar História no século XXI: em busca do tempo entendido. 3 ed. Campinas: Papirus, 2010.

SOUZA, A. P. H. O ensino de História e cultura afro-brasileira: o cumprimento das diretrizes curriculares nacionais. Relatório final PROLICEN com orientação de SILVA, Eliazar João da. Dourados, PPGH/ UFGD, Dourados, 2009.

Concepções do ensino da História regional ensinada no Ensino Médio: práticas docentes em Dourados e Nova Andradina. Dissertação de Mestrado em História/UFGD, 2014.

TAVARES, C. C. da S. História e Informática. In. CARDOSO, Ciro Flamarion; VAINFAS, Ronaldo (Org.). Novos domínios da História. Rio de Janeiro: Elsevier, 2012, p. 301-317.

\section{Fontes impressas consultadas}

PROJETO Pedagógico do Curso de História (PPC História), UFGD, Dourados, 2008.

PROJETO Pedagógico do Curso de História (PPC História), UFGD, Dourados, 2015.

LEPEH (Normas), UFGD, Dourados, 2006.

LABhis (documentos diversos), UFGD, Dourados, 2008.

\section{Entrevistas}

LEITE, Eudes Fernando. Entrevista realizada em 20 de agosto de 2015. Professor do Curso de História/UFGD. 
OLIVEIRA, Benícia Couto de. Entrevista concedida em 31 de agosto de 2015. Professora do Curso de História/UFGD.

ZORZATO, Osvaldo. Entrevista concedida em 31 de agosto de 2015. Professor do Curso de História/UFGD.

Recebido em 19 de novembro de 2014 Aprovado em 18 de dezembro de 2015 